\title{
Article
}

\section{Developing assessments for child exposure to intimate partner violence in Switzerland - A study of medico-legal reports in clinical settings}

De Puy, Jacqueline, Radford, Lorraine, Le Fort, Virginie and RomainGlassey, Nathalie

Available at http://clok.uclan.ac.uk/26147/

De Puy, Jacqueline, Radford, Lorraine ORCID: 0000-0002-6095-3845, Le Fort, Virginie and Romain-Glassey, Nathalie (2019) Developing assessments for child exposure to intimate partner violence in Switzerland - A study of medico-legal reports in clinical settings. Journal of Family Violence, 34 (5). pp. 371-383. ISSN 0885-7482

It is advisable to refer to the publisher's version if you intend to cite from the work. http://dx.doi.org/10.1007/s10896-019-00047-1

For more information about UCLan's research in this area go to http://www.uclan.ac.uk/researchgroups/ and search for < name of research Group>.

For information about Research generally at UCLan please go to http://www.uclan.ac.uk/research/

All outputs in CLoK are protected by Intellectual Property Rights law, including Copyright law. Copyright, IPR and Moral Rights for the works on this site are retained by the individual authors and/or other copyright owners. Terms and conditions for use of this material are defined in the policies page. 
Author Copy: Accepted final draft article for publication in Journal of Family Violence : Special Edition Children and Domestic Violence, to be published June 2019

Title: Developing assessments for child exposure to intimate partner violence in Switzerland - A study of medico-legal reports in clinical settings

Authors: Jacqueline De Puy, Senior Researcher, Violence Medical Unit, University Center of Legal Medicine, Lausanne, Switzerland jacqueline.de-puy@chuv.ch

Lorraine Radford, Professor of Social Policy and Social Work, School of Social Work, Care and Community, University of Central Lancashire, UK, Iradford@ uclan.ac.uk

Virginie Le Fort, Nurse Clinician, Violence Medical Unit, University Center of Legal Medicine, Lausanne, Switzerland virginie.le-fort@chuv.ch

Nathalie Romain-Glassey, Head of the consultations, Violence Medical Unit, University Center of Legal Medicine, Lausanne, Switzerland. Nathalie.Romain@ chuv.ch

\begin{abstract}
:
Purpose: Evidence to inform assessment of needs of children exposed to intimate partner violence (IPV) in health settings is limited. A Swiss hospital-based medico-legal consultation for adult victims of violence also detects children's exposure to IPV and refers cases to the Pediatrics Child Abuse and Neglect Team. Based on a conceptual ecological framework, this study examined the nature and circumstances of children's exposure to IPV described in accounts collected by nurses in consultations with adult IPV victims. Methods: From 20112014, 438 parents ( $88 \%$ female) of 668 children aged 0 to 18 sought medico-legal care from the Violence Medical Unit in Lausanne Switzerland, following assaults by intimate partners (85\% male). As part of the consultation, nurses completed a semi-structured questionnaire
\end{abstract}




\section{CHILDREN'S EXPOSURE TO IPV IN SWITZERLAND}

with victimized parents, recording their answers in the patient file. Victims' statements about the abuse, their personal, family and social contexts, and their children's exposure to IPV were analyzed. Descriptive statistics and qualitative thematic content analyses were conducted to identify, from the victimized parents' accounts, elements useful to understand the nature and circumstances of children's exposure and involvement during violent events. Results: Parent statements on specific violent events described children being present in $75 \%$ of the cases. Children were said to be exposed to, and responded to, severe physical violence, serious threats and insults, in the context of repeated assaults and coercive control. Families, especially mothers, were often coping with additional socio-economic vulnerabilities.

Conclusions: Implications for further developing assessments of children living with IPV, especially in health settings were identified.

Keywords: Intimate partner violence; domestic violence; child maltreatment; children's exposure; child needs assessment; clinical legal medicine

\section{Introduction}

Children's exposure to intimate partner violence (IPV) is now recognized at the international level as a form of child maltreatment (Dubowitz, Hein, \& Tummala, 2018), and as an Adverse Childhood Experience (ACE). Research on ACEs has shown that experiences of abuse during childhood, as well as family stressors such as parental substance abuse or domestic violence have negative effects on lifelong health, and that the combined effects of several ACES are multiplied (Bellis et al., 2014).Due to the harmful effects on development and lifelong health, it is a considerable global public health concern (WHO, 2002; Holt, Buckley, \& Whelan, 2008).

Health services are often a primary point of contact with adult and child victims of IPV and WHO guidelines recommend a ‘case finding approach' for adult victims (WHO, 2013) although methods of identification of children's needs in cases of IPV in healthcare 


\section{CHILDREN'S EXPOSURE TO IPV IN SWITZERLAND}

remain underdeveloped (Lewis et al., 2017). Clinical legal medicine has a unique role to play in this respect, by taking both legal and healthcare aspects of child protection into account. However, there is a lack of research on medico-legal responses and more broadly on health responses to children's exposure to IPV (Howarth et al., 2016).

\section{IPV Exposure is Multifaceted}

While the issue of children exposed to IPV is gaining increasing interest in Switzerland, the evidence on this subject has mostly developed in other countries and is not widely known. For instance, there is still insufficient awareness that children's exposure to IPV extends far beyond "witnessing” or "observing” acts of physical violence. Holden (2003) proposed a "taxonomy" of child exposure to IPV that reflects its many facets: exposure prenatally where there is violence to the mother in pregnancy; where there is direct violence to the mother and also violence to the child from either parent; seeing or hearing the violence; the child intervening to stop the violence; being manipulated or forced into participating; observing the initial effects of the violence; hearing about the violence indirectly; experiences that result from the aftermath; or being seemingly unaware. Other researchers have noted the harmful emotional and developmental impacts of child exposure IPV where there is coercive, controlling behavior that involves the children, often continuing after the parents have separated (Radford and Hester, 2015; Stark, 2007). This work considers how children and young people may experience the direct and indirect consequences of living in a violent home, coping with a climate of fear, 'walking on eggshells' and living with the aftermath of the poverty, social isolation and transience that often results. Taking on responsibility to manage the abusive parent's behavior to protect himself or herself or the mother from post separation violence, harassment or stalking behavior may also cause considerable distress to children and young people (Fortin et al., 2012; Radford \& Hester, 2006; Trinder, Firth, \& Jenks, 2010). 


\section{CHILDREN'S EXPOSURE TO IPV IN SWITZERLAND}

Different children and young people, even those living in the same family, may be affected in different ways and, as with all forms of child maltreatment; the impact varies for children at different developmental stages (Radford et al., 2019). Children and young people however are not passive victims and, at even very young ages, may take steps to act against the violence (Stanley, 2011). Katz's qualitative research with children and young people exposed to IPV towards their mothers found that both parent and child played an active role in supporting one another's safety and recovery (Katz, 2015). While all children need to be safe, their responses, coping strategies and needs for support and for help will not necessarily be the same (Jaffe et al., 2012). All children exposed to IPV are not "doomed to a life fraught with difficulties" (Øverlien, 2010, p. 91).

\section{The Swiss Context}

In Switzerland, two studies have investigated intimate partner violence against women on population samples (De Puy, Gillioz, \& Ducret, 2003; Killias, Simonin, \& De Puy, 2005). These showed that violence and abuse against female victims was characterized by coercive control and dominance from their male partners. They also revealed that female IPV victims talked more readily about the abuse to healthcare and mental health professionals, than to victim services, to the police or justice. A similar trend was found in a survey in the canton of Geneva with both female and male IPV victims (OCSTAT, 2013). A study at the Lausanne University Hospital showed that approximately one out of four patients came to the emergency service following a physical assault (Hofner et al., 2005). This finding was one of the incentives for the creation in 2006 of the Violence Medical Unit (VMU), a medico-legal consultation for victims of interpersonal violence. Since then, the hospital's emergency service has systematically been asking whether injuries resulted from violence and has encouraged victims to make an appointment at the VMU. From the beginning, the VMU has shared information regarding children exposed to IPV, reported by their victimized parent, 


\section{CHILDREN'S EXPOSURE TO IPV IN SWITZERLAND}

with the CHUV's Child Abuse and Neglect Team (CAN Team), a multidisciplinary group including pediatricians, nurses, social workers and psychologists. Through this collaboration, the VMU has been at the forefront of detecting and the CAN Team responding to children's exposure to IPV. Until then, the CAN Team had not dealt with this form of child maltreatment (Cheseaux, Duc Marwood, \& Romain-Glassey, 2013).

As a general rule, IPV and child abuse have largely been constructed in Switzerland as two different social problems, with distinct responses in different services and institutions. In this context, the growing visibility of the issue of children's exposure to IPV challenges these traditional divisions. Over the past two decades, there has been considerable progress in Switzerland in terms of IPV prevention and intervention, following the first national campaign in 1997 and the (still to this day) largely disseminated finding that one out of five women are victims of physical or sexual violence by an intimate partner during their lifetime (Gillioz, De Puy, \& Ducret, 1997). Protection of victims and their children has been a priority of IPV prevention and intervention. However, until recently children were envisioned as witnesses, indirect or collateral victims of IPV. As such, they were not considered as in need of specific assessments. As a result, responses to children's exposure to IPV are still underdeveloped. Among many professionals, and especially in healthcare settings, child maltreatment is envisioned mostly as physical and sexual forms of child abuse (Krüger, Lätsch, \& Voll, 2016, p. XII). Only recently have official statistics been published on children's exposure to IPV in Switzerland. In 2015, the police intervened in more than 14'000 IPV events. In $50-60 \%$ of interventions, children were present, and $40 \%$ of them were under seven years of age (Huber Bohnet, 2016).

Switzerland is a federal state, with large autonomy of each of the 26 cantons, e.g. in healthcare, education, policing. Legislative powers are shared by the Federal, cantonal and communal governments. At the Swiss federal level, an amendment to the Civil Code 


\section{CHILDREN'S EXPOSURE TO IPV IN SWITZERLAND}

regarding protection of children against abuse and maltreatment into effect in 2019. Until then, professional secrecy binding medical doctors, psychologists or lawyers could only be suspended if a criminal offence had been committed. Henceforth, they may turn towards child protection authorities if the interest of the child demands it. So far, only a limited number of other professionals (e.g. teachers, social workers) had a statutory responsibility to report a child's situation to Child Protection Services (CPS) if they suspected a risk for the child's welfare. Under the new law, all professionals in regular contact with children - including daycare, sports or leisure activities facilitators - have a duty to report to CPS when they have concrete knowledge that a child's physical, psychological or sexual integrity is endangered (Office federal de la justice, 2018). Yet, professionals in contact with children and their parents, including pediatricians, lack guidance on how to identify this type of victimization, and when they do, are often at a loss as to what to do about it. In this context, it appears particularly timely to develop evidence-based awareness and knowledge about, and to develop assessments for child exposure to intimate partner violence.

The present study was carried out in one of the settings, at the cantonal level, that has been at the forefront of the protection of victims of domestic violence and child maltreatment (BFEG, 2018). Healthcare professionals in Vaud have since 2004 an obligation to report child maltreatment to the District Court and to Child Protection Services (CPS). The policy of the Cantonal Lausanne University Hospital (CHUV) is that all suspected or actual case of child maltreatment must be referred to the CAN Team, who decide whether to report the case to CPS. However, reports to CPS are not automatic and are reserved to situations where children are considered to be in serious danger, and the parents deemed to be unable to protect them. In all cases of children exposed to IPV brought to the CAN team's attention by the VMU, a member of the CAN Team calls or meets with the IPV victim and makes suggestions for the children's wellbeing (e.g. family or child therapy), and, if the victim agrees, calls the 


\section{CHILDREN'S EXPOSURE TO IPV IN SWITZERLAND}

pediatrician. Rarely are IPV perpetrators seen, and the CAN Team does not meet with the children. As awareness about the consequences of child exposure to IPV has grown in the hospital, assessment criteria have evolved at the VMU and an increasing number of cases have been referred to the CAN-Team. There is, however, no formal child-focused assessment framework to help evaluate the risk of harm, as is, for instance, the case in the UK.

The present study was motivated by the awareness that, in the VMU medico-legal consultation, mothers and fathers who were victims of IPV provided important insight into their children's exposure to IPV and these insights could be a starting point for further developing child-focused assessments in this clinical setting, and build awareness of professionals in other settings. One of the VMU's missions is to offer consultancy and training to a wide range of professionals in contact with IPV victims in healthcare, social work, police or justice. Frequently, when children's exposure to IPV had been detected at the VMU, it was unbeknown to professionals in contact with these children (especially to the children's pediatricians, school or day care staff). Given the large number of children exposed to IPV identified through the VMU, it appeared important to undertake a systematic analysis of these cases and suggest appropriate actions centered on the children's needs. It was also deemed important to take into account the challenges and needs of the IPV victims in their parental role. Such knowledge and recommendations would be useful to a wide range of professionals and institutions involved in IPV prevention and childcare.

\section{Conceptual Framework}

In French-speaking Switzerland, a systemic psychotherapeutic approach of partner violence is quite popular as a conceptual framework to understand IPV (Perrone \& Nannini, 1995; Vannotti \& Morier-Genoud, 2003). This perspective can be in tension with the notion that IPV is a public health problem and a form of violence largely perpetrated against women, as defined in the Istanbul Convention that came into effect in 2018 in Switzerland, or in 


\section{CHILDREN'S EXPOSURE TO IPV IN SWITZERLAND}

cantonal policies of expulsion from home of violent intimate partners. By considering IPV both partners as mutually responsible for the violence, whether "symmetrical", when both partners are supposedly equally violent, or "complementary" when there is coercive control, this model can result in victim blaming and has the limitations of "single factor theories of violence" (Heise, 2011, page 5). It individualizes the problem and largely ignores the important role of gender, power and coercive control in domestic violence (Stark, 2007), where undermining the relationship between the mother and child is a common strategy for isolating the victim and limiting her options to escape (Radford \& Hester, 2006). For instance, in the canton of Geneva, a "psychologisation" in the political and judicial approach to IPV has been criticized, as well as the lack of a gender perspective in the training of social workers or healthcare professionals dealing with families (Roca i Escoda \& Lieber, 2015). Regarding children exposed to IPV, the current practice tends to maintain the bond of a child with both parents, especially fathers. In cases involving IPV, there is a tendency to view the violence as a problem between the parents, unrelated to the parental bond and to disregard it is relevant to fathering. This is harmful for victims and for children living with the violence.

Explanations of violence cannot be limited to the individual and family level, but should take into account social dimensions, such as age, gender differences and inequalities, norms and structures that contribute to the tolerance of violence. Ecological models are useful to understand the range of interactions between individual, family and environmental/ community vulnerabilities associated with complex phenomena such as child maltreatment (Garbarino, 1978; Belsky, 1980 \& 1993), child development (Bronfenbrenner, 1994), or intimate partner violence (Heise, 2011). Levondosky and Graham-Bermann (2001) in particular draw on the ecological theories of child development by Bronfenbrenner (1978), and of child maltreatment (Belsky, 1980; 1993), to conceptualize the inter-related traumatic impact of IPV on women and children. These authors take into account the interactions 


\section{CHILDREN'S EXPOSURE TO IPV IN SWITZERLAND}

between risks and protective factors for individuals (the 'ontological' level), within the family context (the 'microsystem'), within the wider community and family network (the 'mesosystem') and the broader social, political and cultural context (the 'macrosystem'). The advantage of this conceptual approach is that the focus of understanding and developing responses does not rest at the level of an individual's or family's pathology or general failings. The model allows researchers and practitioners to consider that IPV may have a continuum of different impacts that are influenced by different strengths and vulnerabilities of individuals, families, their communities and the wider context, including the intersectional inequalities of age, gender, power and discrimination (Crenshaw, 1990; Yuval-Davis, 2015).

\section{Relevance and scope of the study}

The design of the present study was primarily exploratory and descriptive. This approach was justified by limited research and evidence on children's exposure to IPV in Switzerland, and by the need to investigate how this phenomenon manifested itself and can be addressed in the Swiss context. Gathering such evidence was envisioned as a first step towards informing evidence-based practices, particularly on assessment within the clinical setting.

Bronfenbrenner's (1994) and Heise's (2014) writings on the ecological framework constituted the theoretical backbone of our study. According to these conceptual frameworks, children's exposure to IPV is understood and prevented at the levels of individual risk factors (the ontological level), of interactions in the family (the microsystem level), environmental and neighborhood factors (the mesosocial level) and the broader structural/societal context (the macrosocial context of policies, structural inequalities, poverty etc.). Moreover, although the study is based on the analysis of specific IPV events, our understanding of IPV relies on the clear evidence, including in the Swiss context, that is not limited to outbursts of physical, 


\section{CHILDREN'S EXPOSURE TO IPV IN SWITZERLAND}

sexual or verbal violence, but includes a pattern of coercive, controlling behavior that can target and draw in children.

The purpose of the present study was to identify and examine retrospectively the information available on children exposed to IPV, from the statements collected by nurses from parents who were IPV victims. The research questions were:

1. To what extent does information, collected by nurses during medico-legal consultations with parents who are IPV victims, help understand the circumstances surrounding children's exposure to IPV?

2. In particular, what insight does such information give into the nature and circumstances ofchildren's involvement during IPV events?

3. What further steps should be taken to further develop assessment of children's exposure to IPV?

\section{Method}

\section{The Specificity of Medico-Legal Data}

The VMU has collected extensive medico-legal data from adult IPV victims with children, documenting via victimized parents' reports, also information relevant to their children's exposure to violence. Most victims who come to the VMU have first visited the hospital Emergency Service, where the medical staff are obligated to inform all victims of violence about VMU. But victims are sometimes referred directly by other professionals such as medical doctors, social workers, police officers or lawyers. Consultations at the VMU are always voluntary, by appointment and free. They are available whether or not the victim intends to file a legal complaint. At the start of a consultation, the patient is informed by the attending nurse that the consultation is confidential, except when children were found to be exposed to the violence, because of the hospital regulation to inform the Pediatrics CAN 


\section{CHILDREN'S EXPOSURE TO IPV IN SWITZERLAND}

Team when children might be in danger. It is rare for parents to refuse to pursue the consultation because of this restriction.

The information collected by the VMU was not limited to formal victim statements intended for use in the courts. Many details contained in the medico-legal reports, collected primarily for clinical assessment purposes, were also of interest for research. The semistructured questionnaire that was part of the patient file provided information about the victim's partner, the marital history and current situation; the number and ages of children

(see Appendix 1). In particular, nurses produced accounts, based on the victim's statements, of violent events and children's involvement in much detail, as the victims were asked to recollect the facts shortly after they occurred.

\section{Population}

The sample of case files (patient files) included in the study was selected from the VMU Access database in two stages. Firstly, data concerning the whole population of adult victims of IPV who attended VMU between January $1^{\text {st }}, 2011$ and December 31, 2014 was selected, and secondly, only situations in which children were involved were included. Case files for a total sample of 438 adult IPV victims ( $88 \%$ female) who were parents of 668 children were retrieved. These mothers or fathers had consulted VMU following an assault by a current or former intimate partner (85\% male). Within the four years (2011-2014), most patient-victims consulted the VMU for one violent event, 25 consulted twice ( 22 women and 3 men) for two distinct IPV assaults by the same perpetrator ( $n=463$ consultations). In accordance with the study protocol (2017 - 01736), approved by the Swiss Ethics Committee (CER-VD), use of retrospective data concerning the VMU patients from 2011-2014 was authorized without explicit patient consent, under the condition that all personal data be depersonalized and coded. The citations extracted from the patient files were translated from 


\section{CHILDREN'S EXPOSURE TO IPV IN SWITZERLAND}

French into English for this paper. They comply with the code using a random number in lieu of the name and patient identification number.

\section{Measures}

As part of the usual assessment process with the patients, during the medico-legal consultation, attending nurses filled semi-structured forms that constituted the case files (the patient files, 18 pages) noting verbal responses of patients. Nurses systematically entered responses to structured questions into the Access database after each consultation. Quantitative data were extracted from this Access database. This included: sociodemographic data provided by the 438 victims about themselves, their perpetrators and their children; characteristics of 463 violent events (time, day, location of the assault; injuries sustained; alcohol consumption of perpetrator and victim, verbal threats).

During the exploratory analytical process guided by the first research question - i.e. identifying what information contained in the patient files (case reports) was most useful to understand children's exposure to IPV - it was found that the quantitative data were complemented by the qualitative data from the descriptions of the violent events in which children were present. These gave some insight into the ways children were involved in the violent events and the continuum of violence and abuse. The qualitative data consisted of detailed accounts from the victimized parents, of 243 violent events in which at least one child was present. These accounts were recorded by the nurses to document as precisely and factually as possible events in which physical violence was inflicted on the victim. However, they also described other circumstances surrounding the physical assault, including insults, threats, reactions and responses of the children. Nurses were trained to collect specific factual data during medico-legal interviewing of victim, and this process is similar to a semistructured interview technique. As the victims recounted what happened before, during and 


\section{CHILDREN'S EXPOSURE TO IPV IN SWITZERLAND}

after the violent event, nurses asked them to clarify in as much detail as possible who did what, where, how, when, including the victim, perpetrator, children and other persons present.

\section{Analyses}

The five members of the VMU multidisciplinary research team analyzed the data. The team comprised one nurse, two forensic pathologists in training, the head doctor of the VMU and the sociologist in charge of research projects at VMU. Quantitative analyses were guided by the first and more general research question. Two types of information were found to contribute to the understanding the context in which children lived and were exposed to IPV. Firstly, sociodemographic data provided some insight into the children's family and social environment. Secondly, by looking at the timing and location of violent events, as well as injuries sustained by the victimized parent, their likely implications for the children were envisaged.

After transferring the selected quantitative data from the Access database into a statistical software (IBM SPSS Statistics 23), simple descriptive statistics (percentages, crosstabs by gender, Pearson's Chi-square) were computed from a SPSS database for 438 cases covering the socio-demographic characteristics of 438 victims, of their 668 children, and of the 438 perpetrators. Another database was set up to analyze the 463 violent events.

Qualitative thematic analyses were performed in order to look into the second research question, namely the nature and circumstances of children's direct involvement, where they were present during IPV events. Thematic content analyses (Bardin, 2013) focused on the victims' statement of 243 events in which at least one child was reported to be present. Initially, three members of the research team separately identified significant themes by reading and annotating 100 descriptions of events. The content analysis was partly deductive (looking for indicators of the multifaceted children's involvement identified in previous research, especially Holden's (2003) taxonomy. However, the approach was also partly 


\section{CHILDREN'S EXPOSURE TO IPV IN SWITZERLAND}

inductive, by allowing unforeseen themes to come up. The team discussed jointly their independent findings and agreed on a list of codes that reflected the different ways in which the children were said to be implicated during the violent events. Each researcher subsequently analyzed separately the 143 remaining reports. This process confirmed qualitative thematic saturation and the relevance of the categories covering how children who were present during IPV events were involved (Spencer et al., 2014).

The third research question was addressed in the Discussion section.

\section{Results}

Based on analyses of the data collected by nurses from a majority of mothers and a minority of fathers who were victims of IPV, the findings provide some elements, at various levels of the ecological framework, that help understand the nature and circumstances of children's exposure to IPV, as reported by their parents. The first section presents sociodemographic findings about the children and their families, situating the children within the microsocial (family) and mesosocial environment (socio-economic status of parents). The second section lays out characteristics of the violent events that were most likely to be noticeable by the children, and were examples of the continuing context of violence and abuse in which the children lived, as the victims generally reported a history of IPV over several years, often before or since the birth of their children.

The third section is the core of our study. It considers children's presence and standpoint during the violent events (how the children participated in and responded to the IPV, and were active in the microsocial environment).

\section{The Children, their Family and Social Environment}

The systematic analyses of the data contained in the case files on the child, family and social environment shows a high degree of vulnerability among children and their families. It is noteworthy that a large number of the victims' children were quite young. In a total of 668 


\section{CHILDREN'S EXPOSURE TO IPV IN SWITZERLAND}

children, those aged 0-6 represented the largest group (46.3\%). Children aged 7-12 were the second largest group (32.3\%) and teenagers (aged 13-18) were the smallest age category (21.4\%). Approximately one-third (34\%) were single children, while two thirds of the children had one or several siblings. Eighteen women (4.7\% of female victims) were pregnant at the time of the assault, seven of whom with their first child.

Significant proportions of IPV victims were living with social or economic insecurities, or were financially dependent on their partners (Table 1, column 2 and 3), especially mothers: $49.0 \%$ of female and $28.8 \%$ male IPV victims were without a paid occupation $(\mathrm{p}<.01)$. Among the victims with foreign nationalities, $40.7 \%$ of men and $64.7 \%$ of women had short-term residence permits $(\mathrm{p}<.05)$. Information on the parents or stepparents who perpetrated the violence was provided by the victim parents (see Table 1, columns 4 and 5). The socioeconomic situations of perpetrators (largely fathers or father figures) although generally more favorable than those of the victims (largely mothers), nevertheless revealed similar situations of socio-economic vulnerability.

\section{TABLE 1 ABOUT HERE}

\section{IPV Characteristics and Implications for the Children}

Descriptive statistics concerning 463 violent events were produced, focusing on aspects that were likely to be experienced by the children, whether they were present or not during violent events.

Where, when and how? Data on the timing and location of events showed that these occurred, typically, in the home at times when the children were likely to be present. Children were recorded as being present in $75 \%$ of the events. Events described in the victim statements included accounts of insults, screaming, and serious threats as well as physical assaults. An important finding was that the "violent events" described in statements were practically never limited to one single physical attack. Typically, violent events comprised 


\section{CHILDREN'S EXPOSURE TO IPV IN SWITZERLAND}

several phases over several hours or days, involving a series of violent and abusive attacks, in which the perpetrator pursued the victim in different parts of the premises. When there were attempts by the victims to flee to another room, or exit the building with the children, the violence often escalated in severity. The following excerpt gives one example of the ways children were caught in the middle of an assault and endangered both emotionally and physically. In the mother's words, the perpetrator treated the children as inanimate "objects" he could claim as his possession.

While her husband seized her by the neck, the victim had trouble breathing but managed to tell her son (age 11) to get dressed because they were going to leave the house. Her husband let go of her. She tried to put clothes on their daughter (age 3) but her husband tore them away (...). Her husband grabbed their daughter from her arms, she took the child back and said 'she is not an object'. She had barely time to put the child down as her husband shoved her several times, pushing her from the living room to the bathroom (...) She fell into the bathtub and hit her back and forehead. The boy tried to call the police but the phone was unplugged (...) The victim picked up their daughter and opened the door in spite of her husband trying to prevent her (...) She managed to leave with the two children (4029).

Visible injuries and emotional distress. Records from the medical examinations showed that the victims had injuries that were noticeable by the children several days after they were sustained. The most frequent were bruises and hematomas $(76.7 \%)$ or abrasions $(60.5 \%)$, most of them located on the upper limbs $(70.6 \%)$, on the head $(49.5 \%)$, or on the neck (16.6\%). Fractures were relatively infrequent, but most of the events that resulted in fractures affected women (18 out of 19). Nurses systematically recorded emotional complaints of the victims. The victimized parents often remarked that children who had been present during a violent event subsequently expressed dismay in various ways (e.g. sleep or 


\section{CHILDREN'S EXPOSURE TO IPV IN SWITZERLAND}

digestive disorders reported for very young children, verbal concern for the victim or questions about what happened). Even very young children, according to the victims' statement, indicated they were aware of the violence, for instance:

Mrs. Z said she was rubbing her head and told her daughter it hurt because she fell. Her daughter (3 years old) replied "no, it's daddy who did boom to you and you fell. Then you left (she sought refuge with neighbors) and you came back" (4323).

Recorded incidents where alcohol was mentioned. Standardized questions were systematically asked about alcohol consumption. Perpetrators were said to be under the influence of alcohol in about one third of violent events (35.2\%), and at almost the same rate, victims $(31.3 \%)$ stated that the perpetrator had a drinking problem. It was more unusual for the victim to declare being inebriated at the time of the assault (14.9\%); and when this was the case, both victim and perpetrator were recorded as being under the influence of alcohol (11.2\%). Qualitative analyses indicated that verbal and physical attacks tended to be brutal and persistent whether or not the perpetrator was inebriated. A notable difference however in the victims' account, was that when a perpetrator came home drunk, he insulted and attacked the victim forcefully and immediately. The suddenness of the outburst is likely to be particularly alarming for a child, who as in the following example is the target of her father's rage, and her mother assaulted after trying to protect her daughter:

Her husband was 'very drunk'. He yelled at their daughter (11 years old) because she had closed the door of the house. Mrs X (the victim, his wife) protested, her husband lifted the table on which Mrs X was working, and shoved it on her chest. Mrs X got up to leave through the kitchen door. She looked back (...) and saw that her husband was threatening her with a knife" (4010).

Serious threats. Victims were asked about threats and their precise formulation was noted by the nurses. The content analysis of threats indicated that they were common and of a 


\section{CHILDREN'S EXPOSURE TO IPV IN SWITZERLAND}

serious nature. When children were present, and not necessarily in the same room, hearing these threats could be frightening. Perpetrators made verbal threats in half of the violent events (50.8\%). In 63 events, (13.6\%) there were multiple threats. Almost one in three victim reports included a record of death threats to the victim (32.2\%). One in every eight of the records mentioned threats concerning the children ( $12.1 \%$ of events). The most common threat was to take the children away from the victim (5.8\%), followed by threats to hurt or kill the children $(3.7 \%)$. The formulation of threats made in the presence of children, as conveyed by victimized parents, appeared particularly harsh, for instance:

I will send you back to your country and put our child in a foster home (4129, female victim, mother of a 2-year old).

I will cut myself, injure our daughter and tell the police you did it" (4415, male victim, father of a 1-year old).

He threatened to kill her and their children ( 2 and 4 years old) by pouring gasoline on them and setting them on fire (4377).

A number of times, when children were present, perpetrators threatened victims with knives, even though they were rarely used to stab the victim. Occasionally, a perpetrator was said to have threatened a child directly:

Their son said (age 4), hiding his eyes with his hands, « Daddy, please! His father (mother's perpetrator) told him 'shut up or I'll beat you up' (4211).

Previous violent events. In the majority of cases $(85.6 \%)$, victims said that there had been previous violence from the same perpetrator, before the specific violent event that motivated the medico-legal consultation. There were many indications that the violence and abuse was not limited to discrete incidents of violence but formed a pattern of behavior permeating the families' everyday life. In the following examples, it appears that the children are used in two different ways as a means for the perpetrator to reinforce his power over his 


\section{CHILDREN'S EXPOSURE TO IPV IN SWITZERLAND}

wife. In the first case, because the mother is trying to protect herself and her children by not questioning him, and in the second case, because the husband invokes the mother's parental duty as a means to isolate and control her.

( 8 years previously) Her husband wanted to have sex. When she refused, he slapped her (...) (4 years previously) he punched her in the face in the presence of their 4-year old child. (...) Her husband becomes easily irritated, she makes efforts to calm him down and defuse the violence by all means. She is afraid of him (4247, mother of two children aged 3 and 8 ).

Mrs Y. mentions her husband insults her frequently. She adds that she has no access to the bank account and that her husband gives her a monthly budget, and she can't spend any of the money without his prior consent and then he controls all receipts. Three years ago he pressured her to quit her job, and disapproved the fact that their daughter was in daycare. (4030, mother of a child aged 5).

\section{Children's Involvement in Violent Events}

Victim statements about 243 violent events that documented the presence of children were examined. Even if there were indications of protective actions by and towards the children, they were not included in the analyses presented here. The focus of the analyses was to look at the (potentially) most detrimental aspects of the children's involvement.). The relentlessness of the attacks, aggravated by verbal violence and threats, as described in the qualitative results, helped understand - better than only the statistical results - how upsetting these events had been for the victims and their children.

The findings from the qualitative content analyses of the records indicate that, even for very young children, the children were not passive observers but frequently took active steps in response to the violence. Children's involvement was found to be of three major types: a) parents involved children during the violent event; b) children responded to assaults; and c) 


\section{CHILDREN'S EXPOSURE TO IPV IN SWITZERLAND}

children commented or asked questions after the assault. These different types of involvement were not mutually exclusive.

When Parents Involved the Children. The violence was often initiated in the course of a verbal dispute about the children, mostly around custody and separation, or criticism of the partner's parenting skills. Sometimes, disparaging remarks about the victim were made to the children, and as in this case, as a means to excuse the violence:

According to the victimized mother, her husband told their children "Mommy is mean, she doesn't love daddy, that's why I spanked her" (4249, mother of three children aged 3, 6 and 7).

When children were present, hearing that they were at the center of arguments that resulted in physical violence could cause distress. Another way children were drawn into the event was by being asked to call the police, while facing often life-threatening situations. In the following example, the stress that this type of emergency could represent for the child was apparent:

The victimized mother told their son (age 7) "I cannot breathe... go call the cops" (4249).

The children's responses. Victim statements gave accounts of two types of responses initiated by children to the parental violence: emotional manifestations (cries and screams) and interventions (verbal or physical). Children were often alerted by the noise, especially when sleeping or staying in another room. Often they responded to the violence by protesting verbally:

"He (aged 11) yelled at his mother 'mom, mom, can't you see he's about to kill you!' He added that she had to do something, otherwise they were all going to die (his mother, his sister aged 3 and himself" (4029). 


\section{CHILDREN'S EXPOSURE TO IPV IN SWITZERLAND}

"The mother (victim) wanted to leave with her daughter (age 4). She saw her husband locked them in. She asked her husband for the key but he refused. Their daughter kept repeating 'Daddy, stop!' »(4379).

This citation shows the different manifestations of three siblings:

Their son (age 7) stormed out of his room and jumped on his father, grabbed his hair and hit him (their father was strangling their mother) (...). Their two other children were standing up in their bedroom. Their daughter (age 6) was crying and their younger son (age 3) was agitated and repeated, “There's whacking going on!” (4249).

Children commenting on or asking questions about the violence. In the immediate aftermath of the violence, children asked questions about what had happened:

Her daughter (age 3) asked their mother why she was crying, if she was hurt. She also said, "from now on I will protect you". Her other daughter (age 2) asked their mother 'you OK?' (4273).

\section{Discussion}

The study's purpose was to retrieve and identify information most relevant to the situation of children exposed to IPV, by looking at medico-legal documentation collected from their mothers (less often fathers) who reported an assault by an intimate partner

The first research question sought to identify information that was relevant to understand the context in which children exposed to IPV lived. An important finding was that the parents of the children exposed to IPV, whether victims or perpetrators, often experienced multiple vulnerabilities at the mesosocial level of the ecological conceptual model. Mothers of small children especially were more likely to be without paid work and prone to be financially dependent on their violent partners, limiting their options for moving out with their children. One aspect of coercive control is the social isolation of victims. Those without a professional occupation were likely to be even more deprived of social support. Short-term residency 


\section{CHILDREN'S EXPOSURE TO IPV IN SWITZERLAND}

permits and "third-country" nationalities could also limit job opportunities, financial independence and social support of victims. Recent immigrants from Africa, Latin America or Asia may have had poor knowledge of and limited access to health, social and legal services for themselves and their children. Research into intersectionality has shown that combined discriminations and inequalities such as gender, migration, and poverty increase vulnerability of individuals and families (Yuval-Davis, 2015). Women were the majority of victims of IPV in this study and men the majority of perpetrators and children were exposed to this gendered pattern of violence and coercive control. Assessments of children's needs in Switzerland are often influenced by a psychological systemic analysis of family dynamics (i.e. restricted to the ontological and microsocial levels). This tends to limit responses to family or individual therapies, without addressing the practical and structural barriers and inequalities such as poverty, lack of citizen status, found among families in this study, restricting options to be safe.

Secondly, in response to the second research question - analyses of the IPV events suggested that children's lives were marked by severe and chronic violence in the vulnerable situational context of the family home. One noteworthy finding that in $75 \%$ of records parents gave accounts of children's involvement indicating that it is important to directly ask them about child involvement. The population of victims in our study had already been victimized often repeatedly by the same partner. The violence often occurred at times when the children tended to be present, in the evenings, at night (with risks of disrupting their sleep), or during weekends. 'Events' recorded in the VMU included several assaults and abusive behavior sometimes spanning several days. Children in the early age range, 0-6 years old, were the largest age group among the victims' children. Moreover, a large proportion of the most vulnerable children aged 0-6 years had no sisters and brothers and therefore lacked access to 


\section{CHILDREN'S EXPOSURE TO IPV IN SWITZERLAND}

sibling support as a protective factor (Hornor, 2005). In contrast, those with siblings might have received reassurance and protection from older ones.

Thirdly, one of the most important qualitative findings was that involvement of the children in the violent events was common, substantial and varied. As found in some other studies (Radford \& Hester, 2006), discussions about the children often took place before the violence started and adults regularly called or mentioned the children during IPV events. Infants typically reacted by crying; school age children protested with cries and screams. Teenagers intervened verbally or physically. Children were quite often asked to call the police. Not only were children exposed to serious and repeated violent events, they were also fully engaged actors. Practice responses need to consider this when asking about IPV and when looking at safety and recovery plans.

\section{Age-Related Vulnerabilities}

A large number of the children involved, according to the records, were in the early age group of 0-6 years. The literature clearly indicates specific vulnerabilities regarding IPV exposure in this age group. Even though small children exposed to IPV are particularly at risk in their development, there is also evidence that older children are likely to suffer adverse consequences. Children of all ages are aware of and sensitive to their parent's psychological distress. This study showed that children over seven and especially teenagers were most likely to intervene physically during violent events, and be hurt in the process. Sometimes they were asked to call the police. Children over seven were more likely to be aware of the victims' wounds. Injuries were often located on the head or limbs and difficult to hide.

\section{Exposure Was Always Severe}

As far as assessing the severity of the exposure of the children in the violent events, based on the victims' statements collected by the nurses (qualitative results), it seems that all events that occurred in the presence of the children were harmful to them in several ways. 


\section{CHILDREN'S EXPOSURE TO IPV IN SWITZERLAND}

Moreover, victims' responses about circumstances surrounding IPV events (quantitative results) indicated that children were generally exposed to multiple violent events and a climate of violence and abuse. Nevertheless, a number of elements seemed to be aggravating factors that ought to alert professionals of immediate and urgent need for protection of victims and their children.

It is not just the severe physical violence that harms children, but living in a home where there is a whole pattern of behavior from demeaning and undermining, criticizing, controlling etc. as well as acts of violence and threats. Even if the medico-legal data collected documented in particular violent events and physical violence, these violent events in our study were often accompanied by serious threats, verbal aggressions, and disparaging remarks. The most severe types of threats made by perpetrators in our population were death threats (with a few, but very preoccupying, threats of suicide-homicides). Most of the other threats recorded were also grave ones. Even if the children were not in the same room, given the pattern of events described lasting over a period, it is highly likely they could have heard them. An important finding in our study was that threats were also made about the children. Threats to kill or hurt the children were the most serious ones, but it could also be traumatic to be threatened with being estranged from the other parent. Further research ought to look into the effect of threats on the children and these should be considered as alarm signs in assessments.

In about one third of the events, perpetrators were reported by victims as being under the influence of alcohol, victims often considered that the perpetrator's inebriation had triggered the violence and that their partner had a chronic drinking problem. In view of the body of research on ACEs, the co-occurrence of other ACEs with IPV exposure suggests that this is particularly harmful for children (Bellis et al., 2014).

\section{Limitations}




\section{CHILDREN'S EXPOSURE TO IPV IN SWITZERLAND}

The base for our study was limited by the retrospective, secondary nature of our data, relying on statements collected from adult patients who were victims of intimate partner violence and what these said about the involvement of children. A clear limitation was the lack of direct assessment with children themselves. However, this study offers findings that are a first step in further developing child focused assessments in the clinical context. The emergency room of the hospital and/or the police refer many victims of violence to the VMU. This might explain why a large section of the study's population of victims came from particularly vulnerable segments of the population. They did not constitute a representative sample of IPV victims in the general population, in light of the results of the Swiss prevalence study on IPV against women, which showed no significant differences in victimization according to socioeconomic backgrounds or nationality (Gillioz et al., 1997). Those mothers in more privileged sections of the population might have preferred to consult their family doctor or a private clinic. Nevertheless, the study examined case files pertaining to a relatively large population of IPV victims, and was not restricted to clients of social services, victim services, or parents whose children's situation had been reported to CPS.

Our results rely on the victims' accounts, and therefore reflect their subjective viewpoint on the violence sustained. It has been pointed out that "mothers tend to both underreport and over-report what their children may have seen, heard, been affected by, etc., in term of violence" (Øverlien, 2010, p. 88). When the victims come at the VMU consultation, they are often overwhelmed by multiple problems including financial hardship, and the children's exposure is not necessarily their primary focus. However, subjective bias in patients' reports was partly avoided by the fact that the nurses requested the victims to focus on factual information in the description of the violent events, and not their interpretation of what happened.

\section{Implications for Research}




\section{CHILDREN'S EXPOSURE TO IPV IN SWITZERLAND}

The concurrent accounts by parents, as recorded by the nurses, suggested an important impact on and involvement of young children during the violent events. This important finding warrants further research on how children in this age group are affected and to inform the better identification and assessment of children's needs as recommended by Lewis et al. (2017). However, attention to the differential development impact of exposure to IPV on children and young people of different ages and genders is needed to improve the knowledge base and importantly to inform practice. The results of the present study will be the base for an upcoming study, based on follow-up interviews with the victimized parents whose case files were included in the present study, and with their children. It will be important to find out about the children's trajectories, and what personal, informal and formal resources both children and their victimized parent found, or would have liked to find, in coping with the violence and its consequences.

\section{Implications for Professional Practices}

There is a need to overcome the traditional boundaries between IPV and child maltreatment prevention in the Swiss context, in favor of providing coordinated support to both victimized parents and their children. This type of intervention has proved its effectiveness in other countries (Graham Bermann \& Hugues, 2003). In the Swiss context, the need to reinforce access of parents to early intervention and health promotion in favor of children aged 0-4 has been underlined - especially in socio-economically disadvantaged populations, or in risk situations (substance abuse, mental illnesses) (Hafen et al., 2011). Our results support the need to recognize IPV exposure as an important risk for children's health. Indeed, their access to early intervention is often rendered difficult by the social isolation generated by IPV. There is also a need to recognize children exposed to IPV as "social actors who actively adopt strategies to respond to the violence, thereby resisting it" (Øverlien, 2017) p. 687). Assessments of the children's needs, that are at present made by the CAN Team 


\section{CHILDREN'S EXPOSURE TO IPV IN SWITZERLAND}

based on the information provided by VMU, after talking to the victimized parent and sometimes the children's pediatrician, should in future include seeing and talking to the children and reinforcing their own protective strategies.

In view of our results, and in the context of the reinforced legislation on child protection, there is a need to build awareness about children's exposure to IPV, especially among institutions and professionals working with children. This awareness needs to be placed context with other vulnerabilities, adversities and forms of discrimination in children's lives that will impact on their health and wellbeing. As reported by our population of victims, their children were not only exposed to IPV, but also often to financial strain in the household, alcohol abuse of the perpetrator, or unemployment and insecure residence status of a parent. The threats that these risk factors represent for children's health are documented largely in the Anglophone literature (Bellis et al., 2014; Hughes et al., 2017) and prevention practices (Public Health Wales, 2015), but such knowledge is not common yet among Swiss professionals.

There is however scope to build on the knowledge from this study to inform recording and assessment of childhood experiences of IPV in the health care and clinical setting. There is some evidence that training nurses to administer a structured interview with victims brought a clearer focus on children's well-being as well as the nature, frequency and chronicity of IPV and the broader family vulnerabilities, resulting in an increase of referrals to support services where more specialist assessments can be made. Directly asking about child involvement in domestic violence incidents and careful assessments of the family's socio- ecological context need to be developed and tested in the Switzerland to improve current methods of needs identification and response. There is a need for professionals to be better informed about evidence-based knowledge regarding children's exposure to IPV. This concerns especially professionals in contact with IPV victims, with children, but also other professionals in the 


\section{CHILDREN'S EXPOSURE TO IPV IN SWITZERLAND}

health and social work sectors. Developing direct and safe assessments involving children is however a priority. 


\section{CHILDREN'S EXPOSURE TO IPV IN SWITZERLAND}

\section{References}

Bardin, L. (2013). L'analyse de contenu / Laurence Bardin (2e éd.. ed.): Paris: PUF.

Bellis M.A., Hughes K., Leckenby N., Perkins C., \& Lowey H. (2014). National Household Survey of adverse childhood experiences and their relationship with resilience to healthharming behaviors in England. BMC Medicine, 12-72. doi: 1741-7015/12/72.

Belsky, J. (1980). Child maltreatment: An ecological integration. American Psychologist, 35(4), 320-335.

Belsky, J. (1993). Etiology of child maltreatment: A developmental-ecological analysis. Psychological Bulletin, 114 (3), 413-434. doi: 10.1037/0003-066X.35.4.320

BFEG (2018). Etat de la législation en matière de protection des victimes de violence. Berne : Confédération suisse, Bureau fédéral de l'égalité entre femmes et hommes BFEG.

Bronfenbrenner, U. (1994). Ecological models of human development. Readings on the development of children, 2, 37-43. doi:10.1177/1524838000001004002

Cheseaux, J.-J., Duc Marwood, A., \& Romain-Glassey, N. (2013). Exposition de l'enfant à des violences domestiques. Un modèle pluridisciplinaire de détection, d'évaluation et de prise en charge. Revue Médicale Suisse, 9, 398-401.

Crenshaw, K. (1992) Mapping the margins: intersectionality, identity politics and violence against women of color, Stanford Law Review, 43 :6, 1241-1242

De Puy, J., Gillioz, L., \& Ducret, V. (2003). La famille, un havre de paix? La fin d'un mythe en Suisse. In L. Gillioz, R. Gramoni, C. Margairaz, \& C. Fry (Eds.), Voir et agir. Responsabilités des professionnel-le-s de la santé en matière de violence à l'égard des femmes (pp. 51-72). Genève: Médecine \& Hygiène. 


\section{CHILDREN'S EXPOSURE TO IPV IN SWITZERLAND}

Dubowitz, H., Hein, H., \& Tummala, P. (2018). World Perspectives on Child Abuse and Neglect 2018 (13th ed.). Aurora, USA: International Society for the Prevention of Child Abuse and Neglect.

Fortin, J., Hunt, J., \& Scanlon, S. (2012). Taking a longer view of contact: The perspectives of young adults who experienced parental separation in their youth. Sussex Law School:

Brighton.

Gillioz, L., De Puy, J., \& Ducret, V. (1997). Domination et violence envers les femmes dans le couple. Lausanne: Payot.

Graham-Bermann, S.A., \& Hughes, H.M. (2003). Intervention for children exposed to interparental violence (IPV): assessment of needs and research priorities. Clinical Child and Family Psychology Review, 6, 189-204. doi: 10.1023/A:1024962400

Hafen, M., Zwahl, E., Espeloer, M., \& Ziegele, U. (2011). Better Together'- Prävention durch Frühe Förderung Präventionstheoretische Verortung der Förderung von Kindern zwischen 0 und 4 Jahren. Schlussbericht zuhanden des Bundesamtes für Gesundheit. Luzern: Hochschule Luzern, Soziale Arbeit.

Heise, L. L. (2011). What works to prevent partner violence? An evidence overview. London: STRIVE Research Consortium, London School of Hygiene and Tropical Medicine.

Hofner, M. C., Python, N. V., Martin, E., Gervasoni, J. P., Graz, B., \& Yersin, B. (2005). Prevalence of victims of violence admitted to an emergency department. Emergency Medicine Journal, 22(7), 481-485. doi:10.1136/emj.2003.013979

Holden, G. (2003). Children exposed to domestic violence and child abuse: terminology and taxonomy. Clinical Child and Family Psychology Review, 6(3), 151-160. doi:

10.1023/A:1024906315 


\section{CHILDREN'S EXPOSURE TO IPV IN SWITZERLAND}

Holt, S., et al. (2008). The impact of exposure to domestic violence on children and young people: a review of the literature. Child Abuse and Neglect, 32(8): 797-810. Doi :

10.1016/j.chiabu.2008.02.004

Hornor, G. (2005). Domestic violence and children. Journal of Pediatric Health Care, 19(4), 206-212. doi:10.1016/j.pedhc.2005.02.002

Howarth, E., Moore, T., Welton, N., Lewis, N., Stanley, N., MacMillan, H., Shaw, A., Huber Bohnet, I. (2016). Protection de l'adulte et de l'enfant dans un contexte de violence domestique: moyens d'action et nouveaux enjeux. Zeitschrift für Kindes- und Erwachsenenschutz ZKE, 2, 1-3.

Hughes, K., Bellis, M., Hardcastle, K., Sethi, D., Butchart, A., Mikton, C., Jones, L., \& Dunne, M. (2017). The effect of multiple adverse childhood experiences on health: a systematic review and meta-analysis. Lancet Public Health, 2, 356-66. doi.org/10.1016/S2468-2667 (17)30118-4.

Jaffe, P., Wolfe, D., \& Campbell, M. (2012). Growing up with domestic violence. Cambridge, Massachussetts: Hogrefe.

Katz, E, (2015). Domestic violence, children's agency and mother-child relationships: Towards a more advanced model. Children \& Society 29 (1), 69-79. doi: 10.1111/chso.12023 Killias, M., Simonin, M., \& De Puy, J. (2005). Violence experienced by women in Switzerland over their lifespan: Results of the International Violence against Women Survey (IVAWS). Bern: Staempfli..

Krüger, P., Lätsch, D., \& Voll, P. (2016). Übersicht und evidenzbasierte Erkenntnisse zu Massnahmen der Früherkennung von innerfamiliärer Gewalt bzw. Kindeswohlgefährdungen. Swiss Confederation, Department of the Interior, Federal Social Insurance Office. 


\section{CHILDREN'S EXPOSURE TO IPV IN SWITZERLAND}

Levendosky, A. \& Graham-Bermann, S. (2001) Parenting in Battered Women: The Effects of Domestic Violence on Women and Their Children, Journal of Family Violence, 16:2, 171-192. Doi: 10.1023/A:1011111003373

Lewis, N., Feder, G., Howarth, E., Szilassy, E., McTavish, J., MacMillan, H. \& Wathen, N. (2017). Identification and initial response to children's exposure to intimate partner violence : a qualitative synthesis of the perspectives of children, mothers and professionals. British Medical Journal Open, 8, e019761.

OCSTAT (2013). La violence domestique en chiffres, année 2012. Genève : Office cantonal de la statistique, études et documents, 54.

Office fédéral de la justice (2018). Communiqué du Conseil Fédéral du 27.06.2018. https://www.bj.admin.ch/bj/fr/home/aktuell/news/2018/ref_2018-06-271.html (consulted on 18.12.18).

Overlien, C. (2017). Do you want to do some arm wrestling?: children's strategies when experiencing domestic violence and the meaning of age. Child \& Family Social Work, 22(2), 680-688. doi:10.1111/cfs. 12283

Øverlien, C. (2010). Children exposed to domestic violence. Conclusions from the literature and challenges ahead. Journal of Social Work, 10(1), 80-97. doi: 10.1177/1468017309350663 Perrone, R., \& Nannini, M. (1995). Violence et abus sexuels dans la famille : une approche systémique et communicationnelle. Paris: ESF éditeur.

Public Health Wales (2015). Adverse Childhood Experiences and their impact on healthharming behaviors in the Welsh adult population. Cardiff: Public Health Wales.

Radford, L., \& Hester, M. (2006). Mothering Through Domestic Violence. London: Jessica Kingsley. 


\section{CHILDREN'S EXPOSURE TO IPV IN SWITZERLAND}

Radford, L., \& Hester, M. (2015). More than a mirage? Safe contact for children and young people who have been exposed to domestic violence. In Stanley, N. \& Humphreys, C. (Eds), Domestic Violence and Protecting Children: New Thinking and Approaches. London: Jessica Kingsley.

Radford, L., Richardson-Foster, H., Hargreaves, P., \& Devaney, J. (2019 in press). Research review: The development of domestic violence in childhood and what is known about effective early years prevention responses. London: NSPCC.

Roca i Escoda, M., \& Lieber, M. (2015). La mise en oeuvre et les mutations d'un problème public: Les violences faites aux femmes dans le Canton de Genève (Implementation and Mutations of a Public Problem: Violence Against Women in the Canton of Geneva). Oñati Socio-Legal Series, 5(2).

Spencer, L., Ritchie, J., Ormston, R., O’Connor, W., \& Barnard, M. (2014). Analysis: Principles and Processes. In Ritchie, J., Lewis, J., McNaughton-Nicholls, C., \& Ormston, R. (Eds). Qualitative Research Practice, 2nd edition (pp 267-293). London: Sage.

Stanley, N. (2011). Children experiencing domestic violence: A research review. Research in Practice. Devon: Dartington.

Stark, E. (2007). Coercive control: how men entrap women in personal life. Interpersonal violence. New York: Oxford University Press.

Statistique Vaud (2015). Indicateurs démographiques de la population étrangère dans le canton de Vaud. Lausanne: Statistique Vaud.

Trinder, L., Firth, A., \& Jenks, C. (2010). "So presumably things have moved on since then?" The management of risk allegations in child contact dispute resolution. International Journal of Law, Policy and the Family, 24(1), 29-53. doi: 10.1093/lawfam/ebp010 


\section{CHILDREN'S EXPOSURE TO IPV IN SWITZERLAND}

Vannotti, M., \& Morier-Genoud, C. (2003). Violence domestique: une approche familiale et systémique: Gynécologie-obstétrique. Médecine et hygiène, 61(2457), 2154-2158

WHO (2002). World Report on Violence and Health. Geneva: World Health Organization.

WHO (2013). Responding to intimate partner violence and sexual violence against women: WHO clinical and policy guidelines. Geneva: World Health Organization.

Yuval-Davis, N. (2015). Situated Intersectionality and Social Inequality. Raisons Politiques, 58(2), 91-100. doi:10.3917/rai.058.0091 
Table 1: Socio-demographic characteristics of IPV victims with children and of IPV perpetrators $(\mathrm{N}=438)$

\begin{tabular}{|c|c|c|c|c|c|}
\hline & & \multicolumn{2}{|c|}{ Victims } & \multicolumn{2}{|c|}{ Perpetrators } \\
\hline & & $\mathrm{N}$ & $\%$ & $\mathrm{~N}$ & $\%$ \\
\hline \multirow[t]{3}{*}{ Gender } & Female & 386 & 88.1 & 48 & 11.0 \\
\hline & Male & 52 & 11.9 & 375 & 85.6 \\
\hline & $\begin{array}{l}\text { Male and female (if several } \\
\text { perpetrators) }\end{array}$ & 0 & 0 & 15 & 3.4 \\
\hline Ages & 24 and less & 37 & 8.4 & 17 & 3.9 \\
\hline$\underline{\text { Victims }}$ : Mean & $25-34$ & & & & \\
\hline age $=35.21$ & & 173 & 39.5 & 145 & 33.1 \\
\hline \multicolumn{6}{|l|}{ St.Dev $=8.243$} \\
\hline Perpetrators: & $35-44$ & & & & \\
\hline Mean age $=$ & & 170 & 388 & 154 & 352 \\
\hline 38.82 & & & & & \\
\hline \multicolumn{6}{|l|}{ St.Dev $=9.795$} \\
\hline & $45-54$ & 53 & 12.1 & 95 & 21.7 \\
\hline & $55-64$ & 3 & 0.7 & 18 & 4.1 \\
\hline & $65+$ & 2 & 0.5 & 8 & 1.8 \\
\hline & Missing & & & 1 & 0.2 \\
\hline \multirow[t]{3}{*}{ Nationality } & Swiss & 151 & 34.5 & 157 & 35.8 \\
\hline & UE 28/AELE & 105 & 24.0 & 112 & 25.6 \\
\hline & «Third countries» & 182 & 41.6 & 169 & 38.6 \\
\hline \multirow{3}{*}{$\begin{array}{l}\text { Professional } \\
\text { occupation }\end{array}$} & Yes & 234 & 53.4 & 291 & 66.4 \\
\hline & No & 204 & 46.6 & 143 & 32.6 \\
\hline & Missing & 0 & 0 & 4 & 0.9 \\
\hline Marital status & Single & 85 & 19.4 & & \\
\hline \multirow{4}{*}{$\begin{array}{l}\text { Data available } \\
\text { only for victims }\end{array}$} & Married & 232 & 53.0 & & \\
\hline & Widow(er) & 6 & 1.4 & & \\
\hline & Divorced & 66 & 15.1 & & \\
\hline & Separated & 49 & 11.2 & & \\
\hline
\end{tabular}


CHILDREN'S EXPOSURE TO IPV IN SWITZERLAND

\section{Appendix 1: The Sections of the Patient Files}

- General data: gender*, age*, contact information (address, phone numbers), family doctor

- Sociodemographic data: nationality*, marital status*, education level* and occupation

- Data concerning the violent event that motivated the consultation: date, time and place. Information on the perpetrator(s): number*, gender*, known/unknown to the victim*; nature of the assaults (physical, sexual, psychological violence, deprivation or neglect), threats*, nature of threats, complaint filed or intention to do so*.

- Data concerning the clinical examination centered on the experience and context of the violence: description of the family and social situation, data about the children* number of children, their ages and/or pregnancy of the female patient. Assessment by the nurse or pathologist of children's exposure to the violence. Number of medical consultations related to the violent event, type of previous violence victimization*, location of wounds*; nature of wounds*.

- Conclusions, copy of the assault and battery report established following and based on the consultation.

*multiple choice questions are indicated by an asterisk. The other items correspond to open-ended questions. 